\title{
Optimized data center site selection-mesoclimatic effects on data center energy consumption and costs
}

\author{
Dirk Turek (D) Peter Radgen
}

Received: 10 September 2020 / Accepted: 23 February 2021 /Published online: 5 March 2021

(C) The Author(s) 2021

\begin{abstract}
The effect of the location on the energy consumption of data centers has already been studied in detail on the macro-climatic level. To take advantage of these effects, however, it is usually necessary for the location of data centers to cross international borders. The influence of site changes within national borders and in a small radius of $<100 \mathrm{~km}$ has not yet been quantified. To investigate this, a dynamic mathematical model of the temperature-dependent components of a reference data center was created and the influence on the energy consumption in an area of $240 \times 215 \mathrm{~km}$ in Germany was investigated. It could be shown that even small changes of the location within a $10 \mathrm{~km}$ radius of a location lead to annual energy savings in the recirculating chiller of $9.12 \%$ on average (maximum $56.58 \%$ ). With a freedom of location of $100 \mathrm{~km}$ within national borders, savings of $37.35 \%$ on average (maximum $76.11 \%$ ) are even possible. Location-dependent optimizations are therefore also relevant at local and national level with regard to their influence on energy consumption, and the consideration of mesoclimatic aspects should be an elementary part of the site selection process for data centers in the future.
\end{abstract}

\footnotetext{
D. Turek $(\bowtie) \cdot$ P. Radgen

Institute of Energy Economics and Rational Energy Use, University of Stuttgart, Heßbrühlstraße 49a, 70565 Stuttgart, Germany

e-mail: dirk.turek@ier.uni-stuttgart.de

P. Radgen

e-mail: peter.radgen@ier.uni-stuttgart.de
}

Keywords Data center - Site selection - Energy · Optimization

\section{Introduction}

The demand for computing power is growing steadily worldwide. The main drivers of this demand are digitization, the replacement of analog systems and services through digital alternatives, and general technical advancements in areas such as big data and artificial intelligence. Improvements in data center energy efficiency are not able to fully compensate for the rising energy demand (Koomey and Naffiziger 2016; Avgerinou et al. 2017). As a result, data centers are experiencing a steadily increasing overall energy demand. The energy demand was 153 TWh in 2005 (Masanet et al. 2020) worldwide and increased to $205 \mathrm{TWh}$ as of 2018 (Masanet et al. 2020), which equals an increase of $32 \%$. Optimizations in all aspects of a data center are necessary in the future to reduce the increasing energy consumption of this industry and to minimize the climate footprint of digitization.

Northern hemisphere countries such as Sweden, Norway, and Finland are actively promoting their country as an energy-efficient data center location due to the cold climate (Diguet and Lopez 2019). The colder the ambient temperature of a data center, the more often so-called "free cooling" can be used, which enables a much more energy-efficient operation compared with active cooling by a compression chiller (Acton et al. 2018). The energy- and cost-efficient cooling in combination with 
low electricity prices has led the Big Five (GAFAM/ Google, Amazon, Facebook, Apple, Microsoft) to place their data centers for the European market primarily in the northern half of the continent (Basalisco et al. 2019; Node Pole 2018; Data Center Frontier Special Report 2019). The effect of the ambient temperature at a location on the energy consumption and cost of data center operation has already been studied (Depoorter et al. 2015; Shehabi et al. 2011; Song et al. 2015). These studies considered differences in the local climate on the macro-climatic level meaning that compared locations are hundreds or even thousands of kilometers apart, resulting in significant difference in climate conditions. Depoorter et al. compared five different locations in Europa with Stockholm being the northernmost location and Barcelona being the southernmost. Song et al. compared three locations in the USA with one location in Sweden and Shehabi et al. considered five locations across the USA. All reviewed papers concluded a correlation between low ambient temperature and low operational energy demand, favoring colder climates for data center operation.

But not all computing workload can be outsourced across national borders. This includes data centers that perform tasks for a country's government and its agencies. For a country's government, digital sovereignty is only possible if the infrastructure necessary for state operation remains within its borders. Cross-border placement of data centers is legally impossible for authorities such as the police, the Ministry of Finance or the Federal Supreme Court and therefore requires a data center within national borders. This limits the choice of location to their own country. Due to the federal administration, this can for example limit the choice of location for state authorities in Germany not only to Germany but also to the federal state, narrowing down the potential locations even further. These limitations can also be applicable to businesses as some applications require regional data centers to assure low latency, or to small and medium businesses that want to stay within a country to reduce administrative burden.

Choosing the optimal location for a data center is a highly complex decision process, where many locationdependent factors must be taken into account, such as business taxes, land prices, staff availability, infrastructure, land use plans, and electricity prices (Bubel 2016; Seggern et al. 2014; EnergyNorway 2016; Glatte 2017; Saran and Ramana 2018). In order to make the most rational decision in the choice of location, it is necessary to evaluate as many factors as possible uniformly. The most commonly used unit is the monetary unit as this can be used for economic evaluation and comparability. Many of the location factors mentioned above can be assessed in monetary terms. This includes, for example, the consideration of the land price in relation to the trade tax. The effect of small location variations within a regional area has not yet been quantified. It is therefore currently not possible to take the local temperature as a monetary variable into account when comparing multiple locations within a small area.

In this paper, a dynamic mathematical model of the temperature-dependent components of a reference data center is created. The energy consumption of the cooling system is then calculated depending on the location in a square kilometer resolution in the territory of one federal state of Germany. To account for the different degrees of freedom a data center might have in terms of potential locations, three ranges are defined. The effects of site differences in a small $(10 \mathrm{~km})$, medium $(25 \mathrm{~km})$, and large $(100 \mathrm{~km})$ radius on the energy consumption of the reference data center can thus be investigated. The difference in energy consumption can be compared in monetary terms via the energy price, and with the $\mathrm{CO}_{2}$ intensity of the electricity mix, the climate impact can also be evaluated in dependence of the location. The federal state of Baden-Württemberg was selected for this study because it has topographically relevant variability in the form of mountain regions and large valley zones. Variations in climate in an area like this can be referred to as a mesoclimate, being between global (macroclimate) and local (microclimate). This paper quantifies the impact of mesoclimatic temperature differences on data center energy consumption and thus potential reductions in operating costs. The result can be used as an energetically and monetarily quantifiable decision parameter for the site selection of future data centers.

\section{Methodology}

To quantify the impact of different radii of site selection on the energy consumption of cooling systems, a three tier process is used (see Fig. 1). Initial data for the IT load, operation characteristic, and temperature profiles are needed to calculate a base line for the optimization scenarios. Based on the location-dependent energy consumption, three 
optimization scenarios are defined to quantify the energy saving that are possible by relocating within a $10-, 25-$, or $100-\mathrm{km}$ radius.

Data centers must dissipate heat, generated during IT hardware operation, to prevent components from overheating. From an air conditioning perspective, the entire IT hardware can be idealized as a single heat source with variable output. Real measurements of IT hardware power consumption over the course of 1 year in a data center in Baden-Württemberg were used as a reference and combined with a dynamic load model of a typical UPS with 2MVA peak load. Fig. 2 shows the resulting thermal load that needs to be removed by the cooling system. The thermal load can be represented as a value table $L(k)$ with $k \in \mathbb{N}$. The load profile is similar to typical load profiles of data centers (Radgen et al. 2020).

To dissipate the heat generated by the IT hardware in the data center, there are a number of air conditioning concepts that are similar in their basic function. In this paper, a data center with a hybrid cooling tower and a cooling system capable of free cooling is assumed.

The heat is removed from the IT hardware via airbased ventilation technology commonly referred to as air handling units (AHU) and transferred to a second circular system via a heat exchanger. Based on the current ambient temperature, this second circuit can be divided into the two operating modes of free cooling and compression cooling. Free cooling is only possible if the ambient temperature is low enough to dissipate the heat load to the environment without using a compression refrigeration machine (see Fig. 3). If the ambient temperature is low enough, the coolant warms at the heat exchanger and is pumped to a cooling tower (also referred to as a recooler) where it gets cooled and recirculated to the heat exchanger. This process has a relatively low energy consumption, as the only energy requirement comes from the fans in the cooling tower and the pumps to circulate the coolant.

If the ambient temperature is so high that free cooling operation is not possible, a compression chiller (also referred to as direct expansion (DX) chiller) is used to capture the heat flow of the IT hardware and dissipate it at a higher temperature via the cooling tower (see Fig. 4). This requires more energy than free cooling, as additional energy must be used to operate the chiller.

The switching temperature between these two operating modes depends on the acceptable temperature in the data center and the quality of the cooling technology used. For the reference data center, a coolant temperature of $25 / 20^{\circ} \mathrm{C}$ is assumed, which is average for a data center in Europe and within the guidelines for data center temperatures stated by ASHRAE (Avgerinou et al. 2017; ASHRAE 2016).

In both operating modes, a recooler is used to dissipate the heat to the ambient air ("cooling tower" in Figs. 3 and 4). Both dry and hybrid cooling systems can be used for this purpose. Dry cooling systems transmit the heat to the environment via forced convection, with fans being responsible for air transport. Hybrid cooling systems can additionally use the effect of evaporative cooling by applying water on the surface of the heat exchanger, which cools the heat exchanger by the phase change during evaporation. In order to reduce the water consumption, it is possible to only partially spray the recooler with water.

The operating characteristic of a cooling system with a hybrid chiller for a cooling capacity of $1.000 \mathrm{~kW}_{\mathrm{th}}$, as seen in Fig. 5, was defined for the reference data center based on manufacturer data, own calculations, and data from Koch (2020). The operating characteristics can be represented as the function $K(t)$. Switching between free cooling and compression cooling in the reference data center is done at $16^{\circ} \mathrm{C}$.

In Fig. 5, the operating modes are clearly recognizable. At temperatures below $10^{\circ} \mathrm{C}$, the system is operated with dry free cooling. Energy consumption increases with higher temperatures, as the fan speed of the recirculating chiller increases in order to continue cooling the coolant to $20^{\circ} \mathrm{C}$. The base load of the circulation pumps is temperature independent and remains constant. Above $10{ }^{\circ} \mathrm{C}$, the recooler is additionally sprayed with water, which reduces the necessary speed of the fans and thus the energy requirement, but results in a constant water consumption. At an outside temperature above $16^{\circ} \mathrm{C}$, it is no longer possible to achieve a temperature of $20^{\circ} \mathrm{C}$ in the return flow via the recooler. At this point, the compression chiller is operated and the recooler now serves as a condenser for the cooling process. In this case, it is only necessary to cool the cooling medium down to $29^{\circ} \mathrm{C}$, which can be accomplished with a lower fan speed. The heat exchanger is partially sprayed with water from $19{ }^{\circ} \mathrm{C}$ and the entire heat exchanger is sprayed with water above $24{ }^{\circ} \mathrm{C}$ in order to make maximum use of the adiabatic cooling effect.

In Baden-Württemberg, the local climate can be taken into account for the dimensioning and design of data center cooling systems based on DIN 4710 using six different reference climate zones (Norm DIN 4710 2003). The currently valid version of DIN 4710 was 


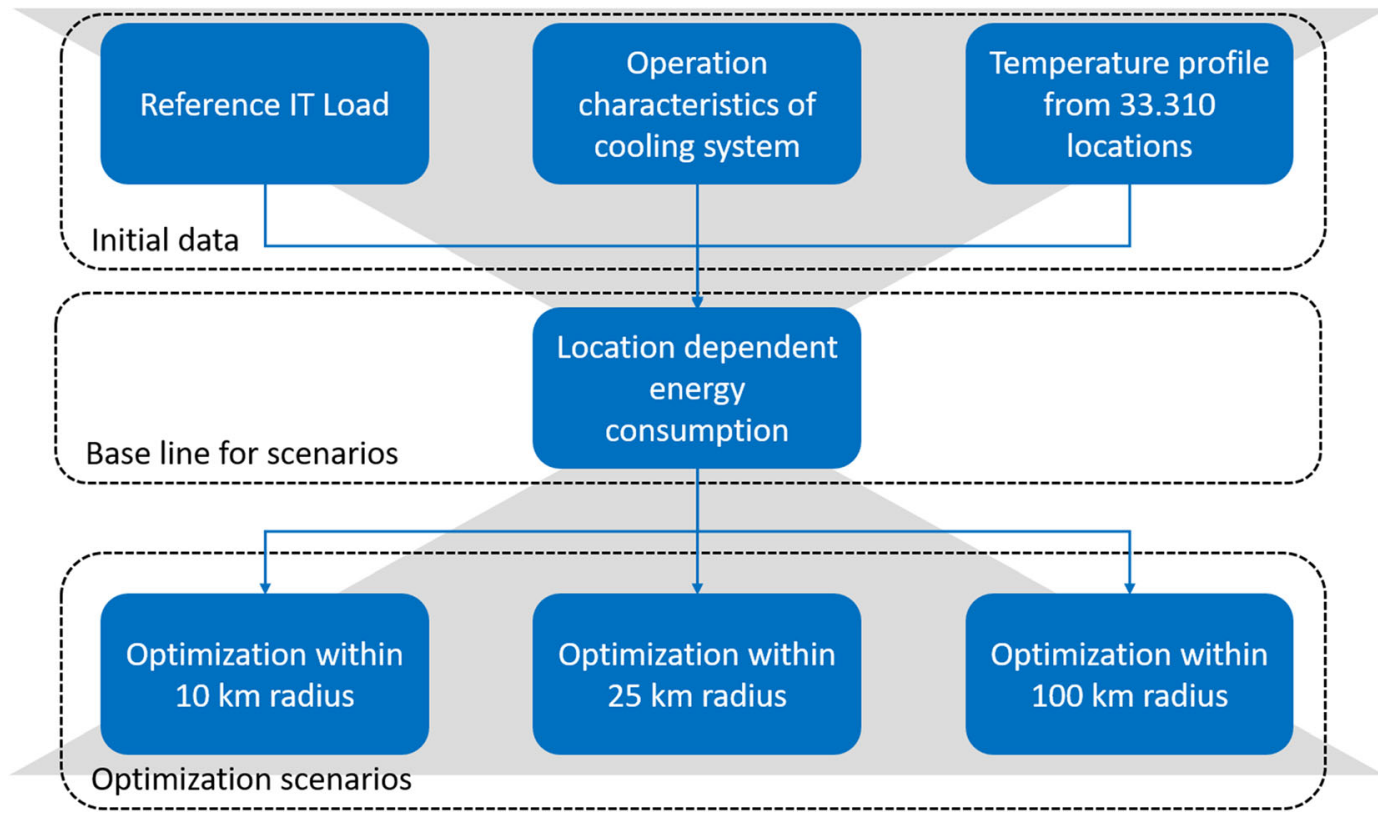

Fig. 1 Three tier process used in this paper

published in 2003 and is based on the data collected from 15 measuring stations in the period from 1961 to 1990. For the consideration of local differences in the energy consumption of the cooling systems, this classification is, however, only of limited use, since small spatial fluctuations within the climate zones cannot be considered. However, spatially high-resolution data sets on temperature conditions are available for Germany (Krähenmann et al. 2016). The German Weather Service (Deutscher Wetter Dienst DWD) offers temperature data in hourly resolution at the square kilometer level as public data sets for the years 1995 to 2012. For
Baden-Württemberg, this results in 33.310 individual data sets indicating the hourly temperature profile per square kilometer. The year 2012 was used as the data basis for the following calculations as it is the most recent data set available.

For the selected reference year 2012, the data set can be represented as a three-dimensional matrix $T \in \mathbb{N}^{3}$ with 292.6 million data points. The east-west expansion can be expressed here as abscissa $j$, the north-south expansion as ordinate $\mathrm{i}$, and the temporal expansion as appliqué $k$. The ambient temperature $T_{\mathrm{i}, \mathrm{j}, \mathrm{k}}$ is given in this matrix in steps of $0.1{ }^{\circ} \mathrm{C}$. The location- and time-

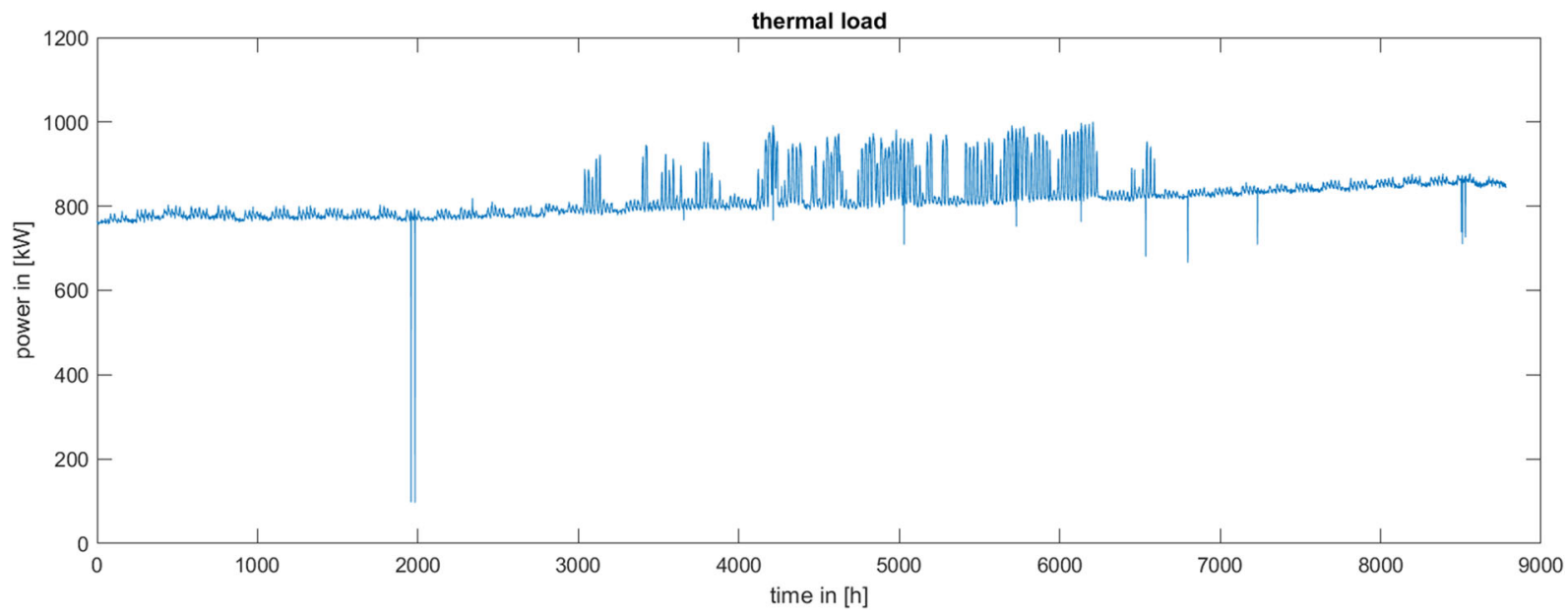

Fig. 2 Power consumption of the IT hardware that was used for the reference data center 


\section{Free cooling schematic}

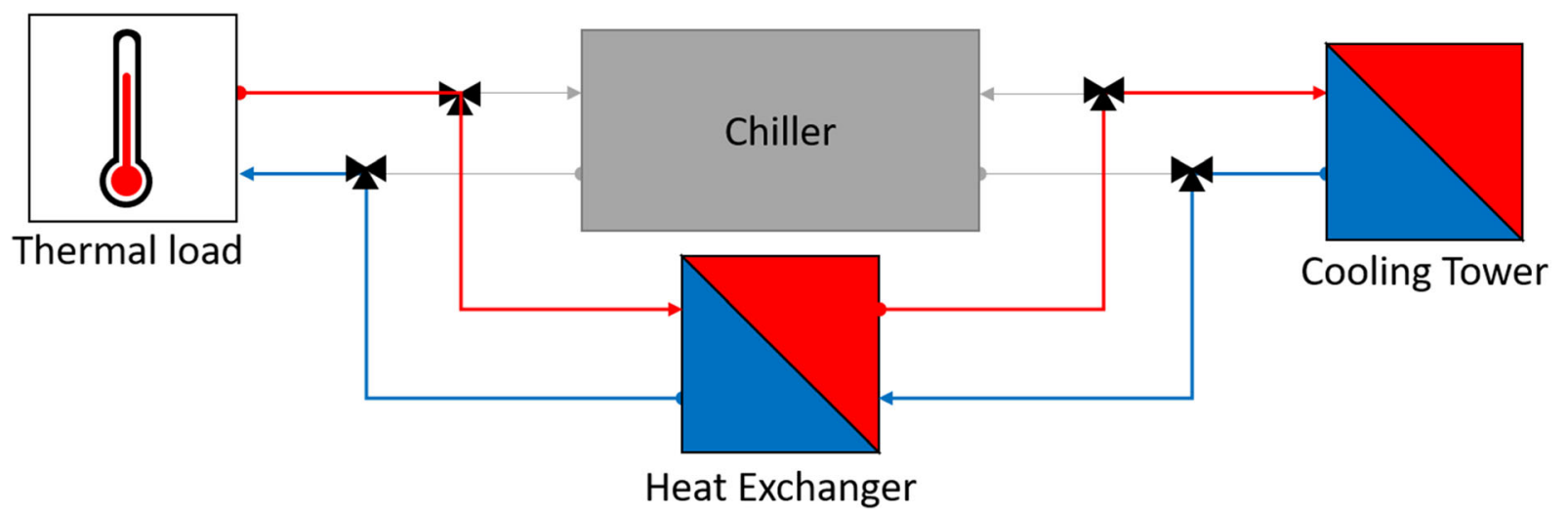

Fig. 3 Heat transfer schematic in the free cooling mode

discrete power consumption $P$ of the cooling system can be calculated with the time-discrete IT power $L(k)$, the IT maximum power $L_{\max }$, and the power consumption of the cooling system $K(t)$ at the temperature point $T_{\mathrm{i}, \mathrm{j}, \mathrm{k}}$ using formula (1). As seen in Fig. 2, the IT-Load is constant with only small fluctuations. This consistent load profile is typical for data centers (Radgen et al. 2020). Therefore, a linear correlation between the ITLoad and the cooling system can be assumed as the cooling system operates close to its design load. It has to be noted that this correlation is not applicable to load profiles with rapid changes due to day/night or workday/ weekend fluctuations.

$P_{i, j, k}=K_{\left(T_{i, j, k}\right)} \times \frac{L_{(k)}}{L_{\max }}$

The location- and time-discrete power consumption can then be summed up via the applications $k$, in order to indicate, as location-discrete energy consumption $E_{\mathrm{i}, \mathrm{j}}$ the annual energy consumption in the study area (see formula (2)).

$E_{i, j}=\sum_{k=1}^{8784} P_{i, j, k}$

The two-dimensional visualization of $E_{\mathrm{i}, \mathrm{j}}$ with a color scale in the value space between 0 and $550 \mathrm{MWh}$ is shown in Fig. 6. The energy consumption $E_{\mathrm{i}, \mathrm{j}}$ of the recooler lies between 202.55 and $553.82 \mathrm{MWh} / \mathrm{a}$ in the state due to the different temperatures. The arithmetic mean of the energy consumption is $420.47 \mathrm{MWh} / \mathrm{a}$. In terms of energy, the state capital Stuttgart at the location $E_{134,122}$ can be identified as one of the most disadvantageous data center locations (see Fig. 6).

To determine the influence of location variation, three degrees of freedom in the form of radii were

\section{DX cooling schematic}

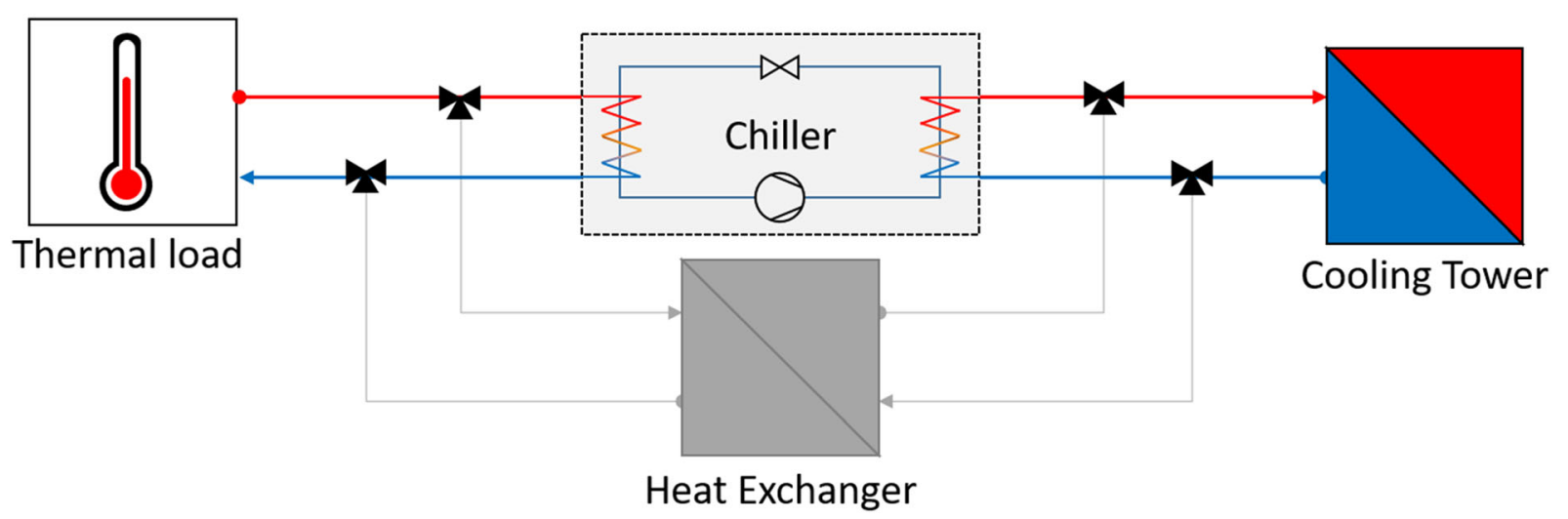

Fig. 4 Heat transfer schematic in the compression cooling mode 


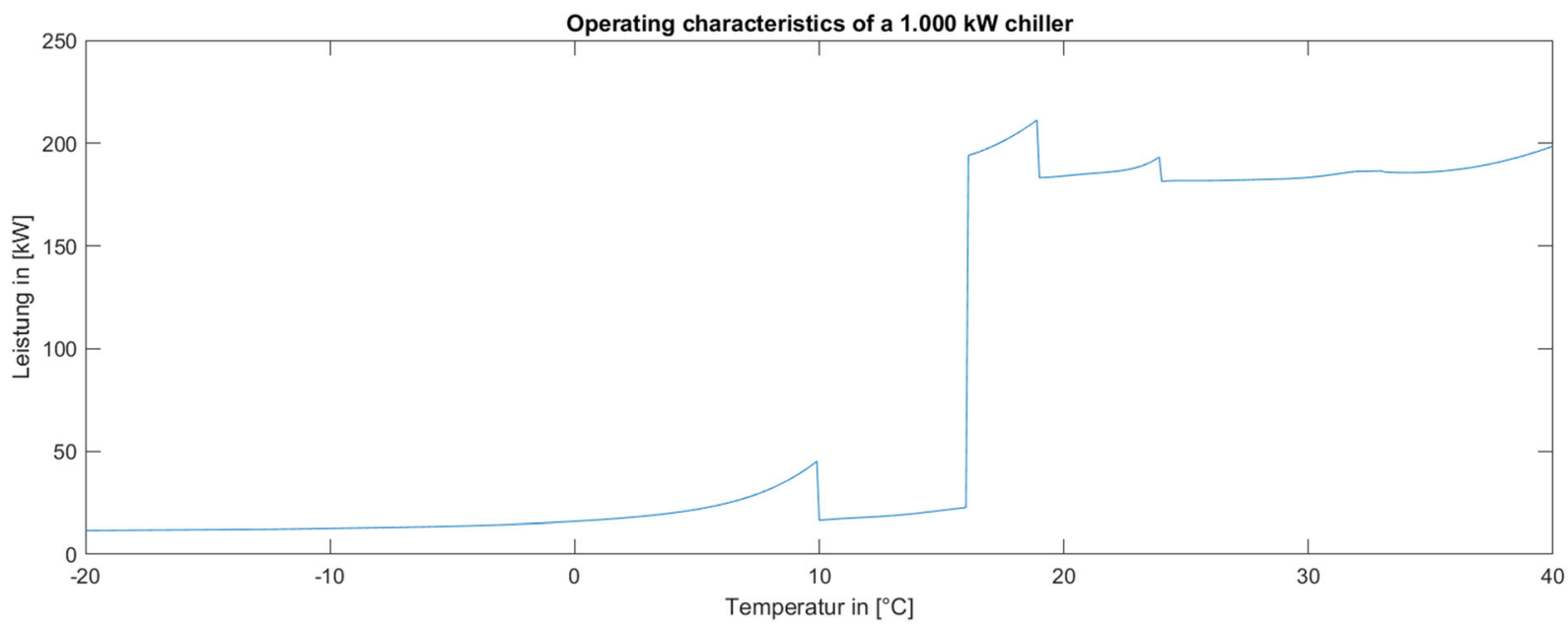

Fig. 5 Power consumption $K$ as a function of temperature $(t)$ for the recirculation chiller

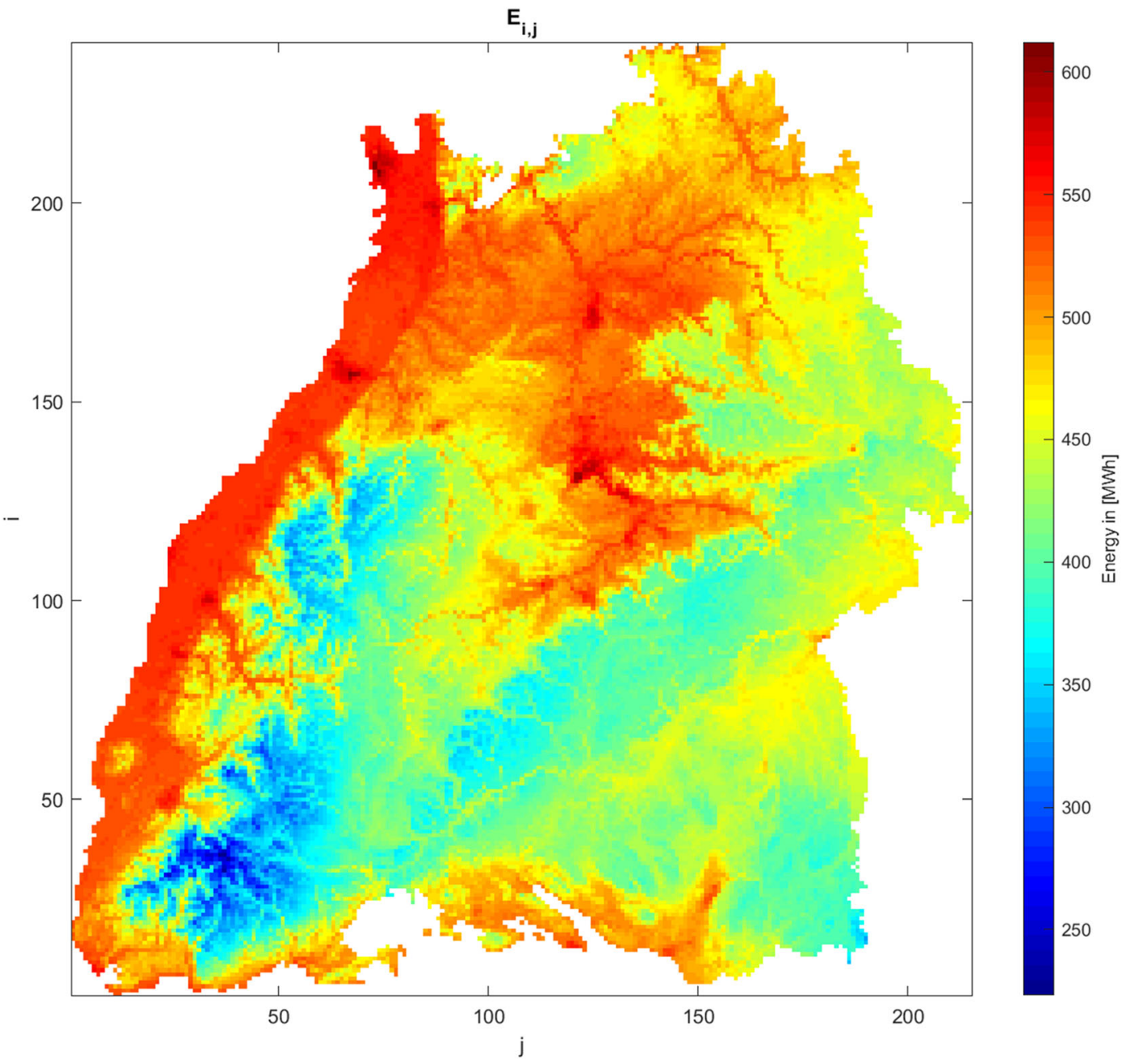

Fig. 6 Energy consumption of the cooling system per year dependent on location 


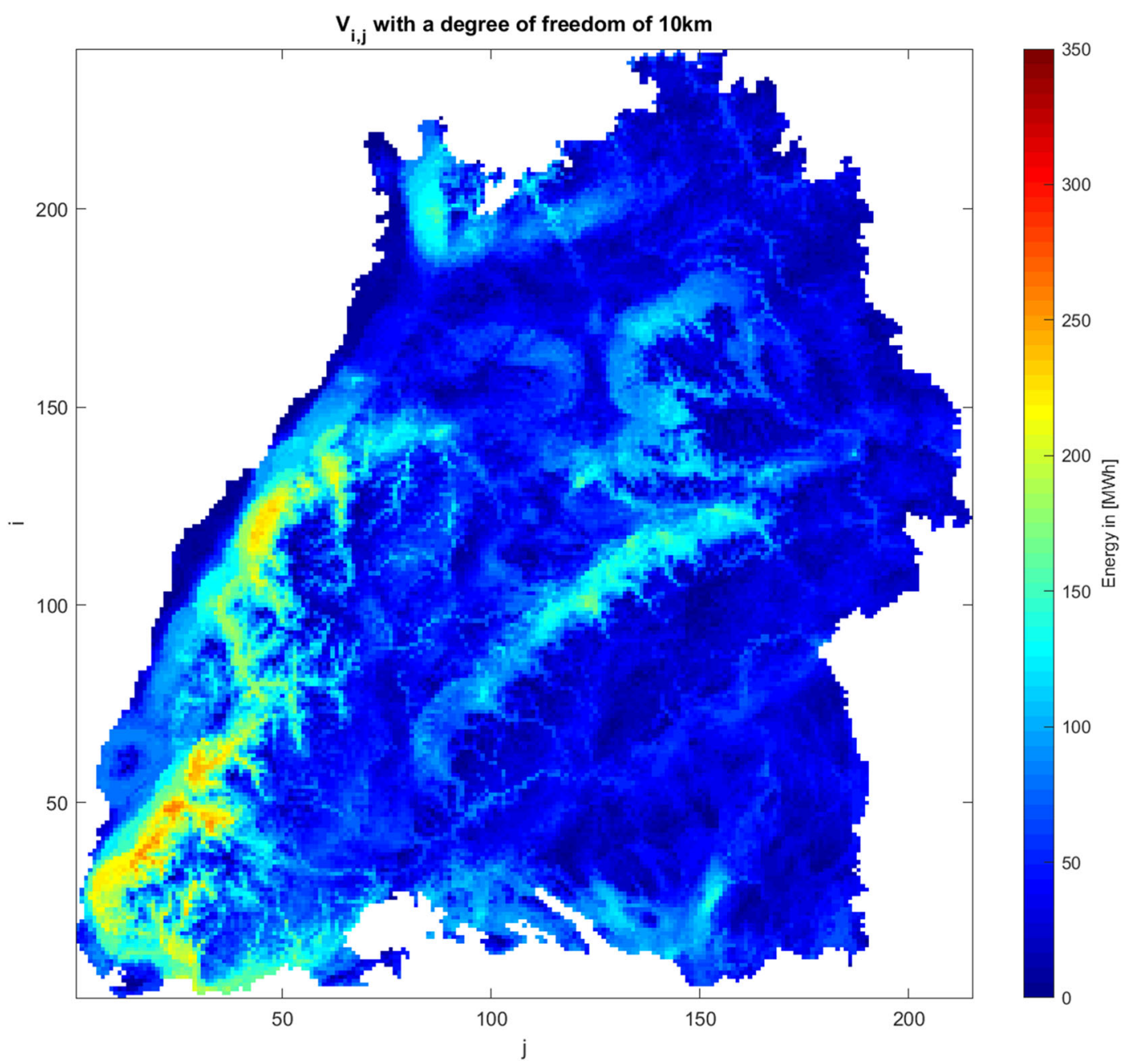

Fig. 7 Optimization potential with a radius of $10 \mathrm{~km}$ of freedom

defined. These correspond to a radius of 10, 25, and 100 $\mathrm{km}$. Within these radii, the optimization potential $V_{\mathrm{i}, \mathrm{j}}$ that would be possible by a change of location within the corresponding radius is calculated for each square kilometer point (see formula (3).) for the 10-km radius).

$$
V_{i, j}=E_{i, j}-M i n(E) \text { for } E\{\} \Leftrightarrow\left|\overrightarrow{E_{i, j} E}\right|<10
$$

In order to convert the energetic values into monetary and ecological values, a location-independent electricity price of $0.16 € / \mathrm{kWh}$ and a location-independent $\mathrm{CO}_{2^{-}}$ emission factor of $401 \mathrm{~g}_{\mathrm{CO} 2} / \mathrm{kWh}$ is defined. The electricity price of $0.16 € / \mathrm{kWh}$ corresponds to the average industrial electricity price in Germany in 2019 (Bundesnetzagentur 2020). The $\mathrm{CO}_{2}$ emission factor of $401 \mathrm{~g}_{\mathrm{CO} 2} / \mathrm{kWh}$ corresponds to the average electricity mix in Germany in the year 2019 (Icha 2020).

\section{Results}

The saving potentials by a local shift within a radius of $10 \mathrm{~km}$ are visualized in Fig. 7 and highlighted by a color scale in the value range between 0 and 350 $\mathrm{MWh} / \mathrm{a}$. The optimization potential is particularly pronounced in the southwest of the study area and corresponds to the western valley side of the Black Forest low mountain range. The median of the optimization with a degree of freedom of $10 \mathrm{~km}$ is 42.44 $\mathrm{MWh} / \mathrm{a}$, with a maximum value of $264.05 \mathrm{MWh} / \mathrm{a}$. This corresponds to a monetary median of $6.790 € / \mathrm{a}$ and an ecological median of $17.018 \mathrm{~kg}_{\mathrm{CO} 2} / \mathrm{a}$.

The results can also be displayed in a histogram that shows the frequency distribution of the optimization potentials in MWh steps (see Fig. 8). The histogram for a site optimization in a radius of $10 \mathrm{~km}$ increases 


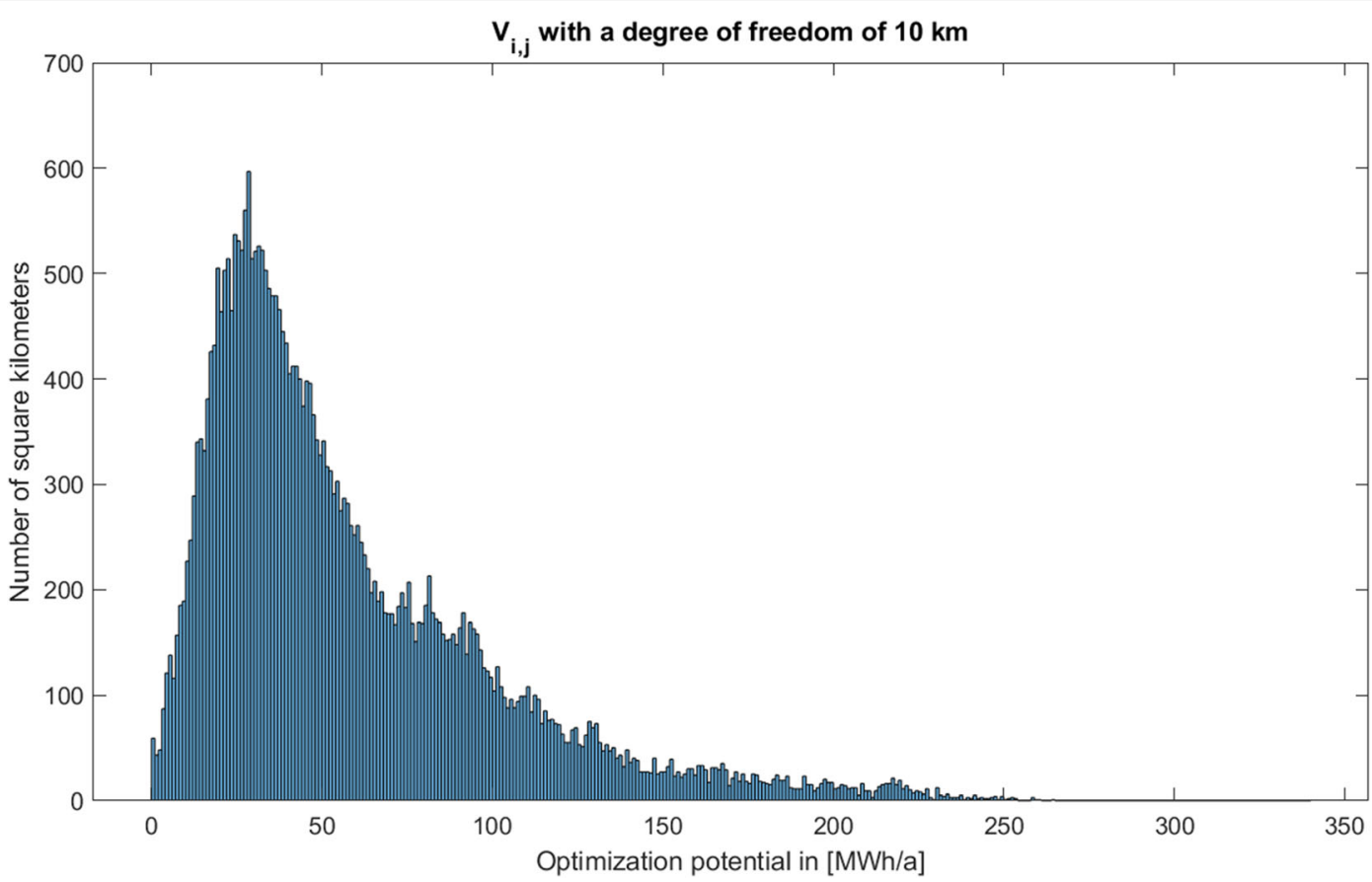

Fig. 8 Histogram of the $10 \mathrm{~km}$ optimization

approximately linearly and has its frequency maximum at 25-26 MWh/a. After the maximum frequency, the frequency of the optimization potential in the histogram decreases exponentially.

If the radius of the site selection is increased to 25 $\mathrm{km}$, the median of the optimization potential increases to 81.09 MWh/a. This corresponds to a monetary and $\mathrm{CO}_{2}$ savings potential of $12.975 € / \mathrm{a}$ and $32.520 \mathrm{kgCO}_{2} / \mathrm{a}$, respectively. The energy optimization maximum with a degree of freedom of $25 \mathrm{~km}$ is $332.02 \mathrm{MWh} / \mathrm{a}$. The optimization potential is more pronounced in the southwestern part of the study area, although the northern part of the Swabian Alb and the central zone of the Upper Rhine Plain also show increases potentials. The eastern part of the study area is characterized by a low and almost homogeneous optimization potential (Fig. 9).

The histogram for a location optimization in a radius of $25 \mathrm{~km}$ (see Fig. 10) shows a flatter course shifted to the right compared with the histogram in Fig. 8. The frequency maximum is $53-54 \mathrm{MWh} / \mathrm{a}$, with a local frequency maximum in the range of 201-202 MWh/a.

If the degree of freedom in the choice of location is increased to $100 \mathrm{~km}$, the median optimization results in 174.52 MWh/a, and the maximum is at $355.21 \mathrm{MWh} / \mathrm{a}$. The degree of freedom of $100 \mathrm{~km}$ enables a monetary saving of $27.923 € / a$ and an ecological saving of 69.982
$\mathrm{kg}_{\mathrm{CO} 2} / \mathrm{a}$ in the arithmetic mean. Due to the higher degree of freedom of location, this optimization primarily results in higher potentials for the area of the southern Rhine trench and moderate potentials for the entire western part of the study area (Fig. 11).

The histogram for a site optimization in a radius of $100 \mathrm{~km}$ has the frequency maximum between 175 and $176 \mathrm{MWh} / \mathrm{a}$ and shows an even more uniform distribution compared with previous calculations (see Fig. 12).

The achievable savings increase from an energetic, economic, and ecological point of view as the degree of freedom increases. The absolute energy minimum lies at the location $E_{36,37}$. At this location, the reference data center that requires only $223.23 \mathrm{MWh} / \mathrm{a}$ to operate the cooling system. The absolute energy maximum lies at the location $E_{209,73}$. At this location, the cooling system of the reference data center requires $612.16 \mathrm{MWh} / \mathrm{a}$.

The optimization potential was calculated for a reference data center with an average IT performance of $0.776 \mathrm{MW}$. In order to put the results into perspective, it is helpful to extrapolate them to the entire data center landscape in Baden-Württemberg. For an extrapolation, however, no absolute values are available for the federal state but for Germany as a whole. The Borderstep Institute calculates the energy consumption of data center IT hardware in Germany to be 8.5 TWh for the year 2018 


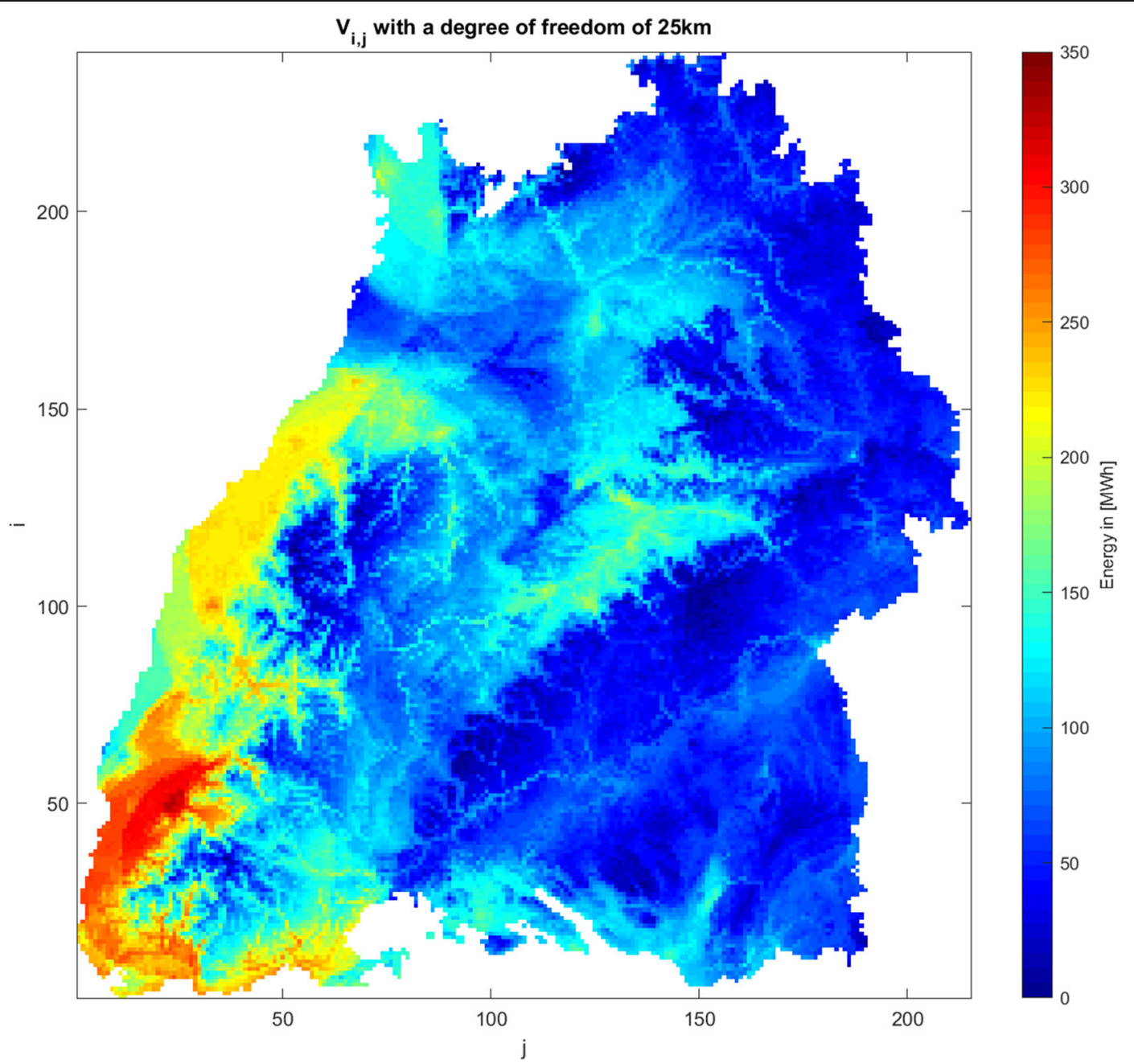

Fig. 9 Optimization potential with a radius of $25 \mathrm{~km}$ of freedom

(Hintemann 2018). Baden-Württemberg as a state of Germany has therefore a data center related IT energy consumption below this value. For the federal state, three scenarios are used to analyze the impact of the location optimization. The scenarios vary based on the energy consumption and are defined as scenario A with $0.5 \mathrm{TWh}$, scenario B with $1 \mathrm{TWh}$, and scenario $\mathrm{C}$ with 1.5 TWh. This corresponds to an average load of 57 MW, $114 \mathrm{MW}$, and $171 \mathrm{MW}$, respectively, in the state of Baden-Württemberg.

It should be noted that this extrapolation is based on the assumption that all data centers are operated with a hybrid cooling tower like in the reference data center used in this paper. This is not the case in the heterogeneous landscape of data center cooling technologies.
Therefore, the results of the real data center landscape will slightly differ from this extrapolation. But the effect can be assumed to be low as a hybrid cooling tower lies, from an energy consumption perspective between a dry and an open cooling tower.

Assuming that the current data centers in BadenWürttemberg were located without the consideration of mesoclimatic saving potentials, it is reasonable to assume an even distribution of the data centers within the temperature spectrum. This not optimized site selection without consideration of the ambient temperature, results in a theoretical total savings potential between 12.837 MWh/a and 38.510 MWh/a that can be achieved with the $100 \mathrm{~km}$ degree of freedom for the federal state. This results in an economic potential between 2.05 and 


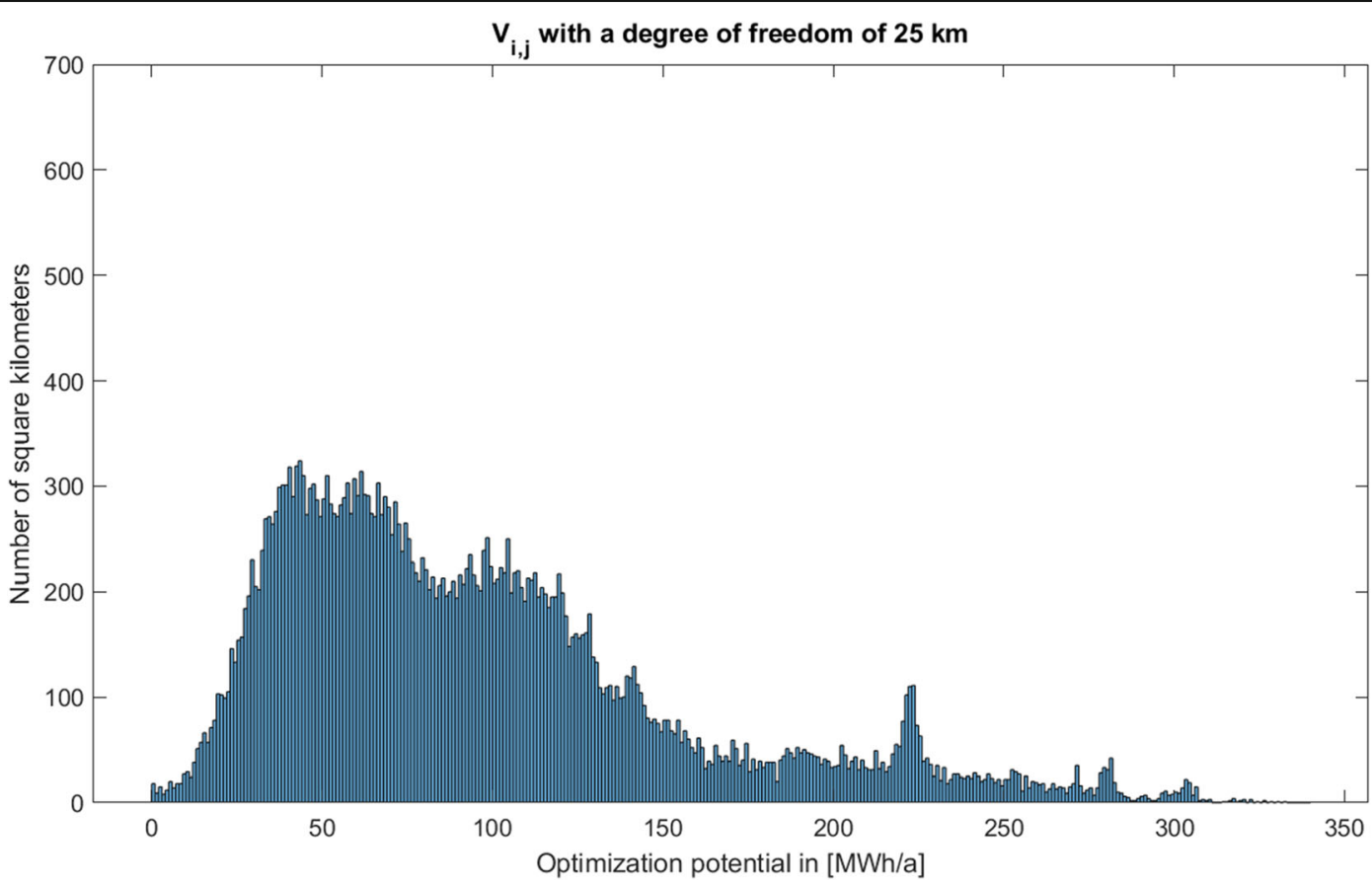

Fig. 10 Histogram of the $25 \mathrm{~km}$ optimization

6.16 million $€ / \mathrm{a}$ and an ecological potential between 5.147 and $15.442 \mathrm{t}_{\mathrm{CO} 2} /$ a. Compared with a random site selection, the $25-\mathrm{km}$ optimization results in an overall energy saving potential between 5.964 and 17.893 $\mathrm{MWh} / \mathrm{a}$ as well as an economic potential between 0.954 and 2.862 million $€ / \mathrm{a}$ and $\mathrm{CO}_{2}$ saving between 2.391 and $7.175 \mathrm{t}_{\mathrm{CO} 2} / \mathrm{a}$. In the $10-\mathrm{km}$ optimization case, the energetic potential is reduced to between 3.122 and 9.365 MWh/a which corresponds to between 0.499 and 1.498 million $€ / \mathrm{a}$ in monetary terms and between 1.251 and $3.755 \mathrm{t}_{\mathrm{CO} 2} / \mathrm{a}$ in ecological terms (see Table 1).

\section{Discussion}

In the model used for the energy consumption of the recirculating chillers (see Fig. 5), the air humidity is not considered dynamically, but generalized to all locations based on a temperature-humidity correlation according to DIN 4710 for the Stuttgart location. This can lead to a distortion of the results, since the correlation between temperature and humidity is influenced by various topographic and climatic factors and is therefore different at each location. The distortion affects the energy consumption of the recoolers in the hybrid cooling phase.
The primary difference in energy consumption is due to the use of the compression refrigeration machine (see Fig. 5), which is not influenced by humidity. A consideration of humidity on the energy consumption of the recoolers depending on the location is therefore an open research question and should be considered in future models. The influence of altitude on energy consumption of cooling systems should also be investigated in further research.

The model uses the operation characteristics of a cooling system with a single chiller (see Fig. 5). This is not directly applicable for all data centers, as certain operators require multiple cooling towers to provide redundancies. Power consumption results from a single cooling tower model might differ from facilities with redundant cooling towers, but it can be assumed that these differences are small. It should be noted that the CapEx of a redundant cooling system is significantly higher, but this is not the focus of this paper as it only focuses on the OpEx.

In this paper, the ecological potential is calculated by the average $\mathrm{CO}_{2}$ footprint of the German electricity mix for all locations in the same way. The purchase of green electricity certificates or the local production of renewable energy as an option to 


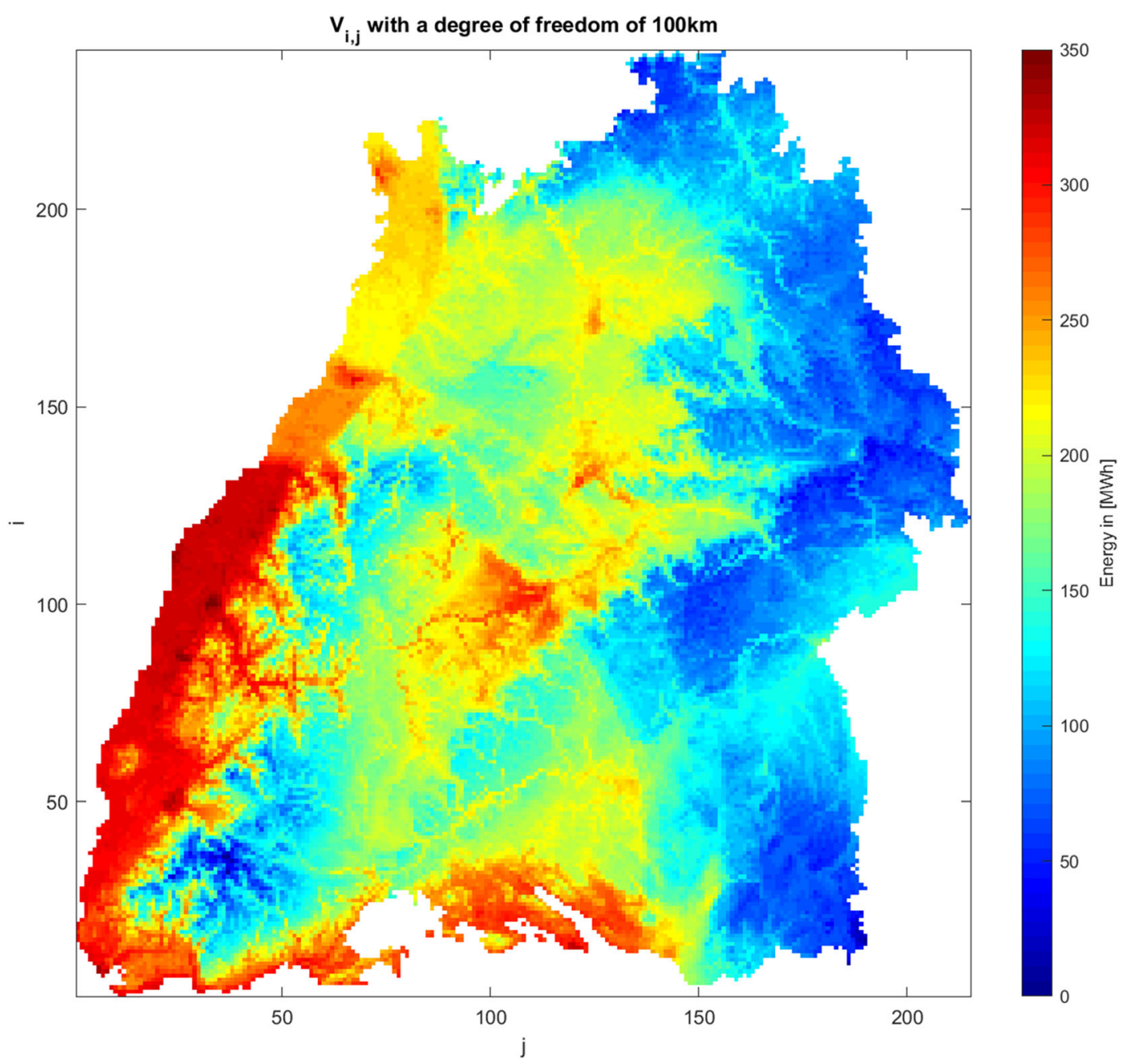

Fig. 11 Optimization potential with a radius of $25 \mathrm{~km}$ of freedom

reduce the $\mathrm{CO}_{2}$ intensity of electricity consumption and thus the environmental impact is not considered in this work. Data center operators can reduce the $\mathrm{CO}_{2}$ footprint of purchased electricity to zero, regardless of the actual power consumption, by means of green power contracts. However, based on the real electricity supply, which is physically determined, it can be argued that it is a sufficient assumption to equate the electricity consumption within the study area with the average electricity mix. The evaluation whether the purchase of green power certificates is primarily used for "green washing" is currently part of the controversial discussion.

The energetic optimum at position $E_{36,37}$ is located in the community of Feldberg in the Black Forest and is on the mountain of the same name (Feldberg), which is the highest mountain in the state of BadenWürttemberg. The economic development of this location for data centers is very unlikely due to the local conditions. It is therefore uncertain whether the optimization potential is representative for a degree of freedom of $100 \mathrm{~km}$, since with this degree of freedom, more than $1 / 3$ of the federal state area already refers to this location in its optimization. Energetically almost equivalent $(+5 \%)$, however, there is already a television tower at a minimal distance at position $E_{35,36}$ which indicates at least theoretical accessibility in the close proximity.

The general viability of other locations should also be critically examined. In addition to 


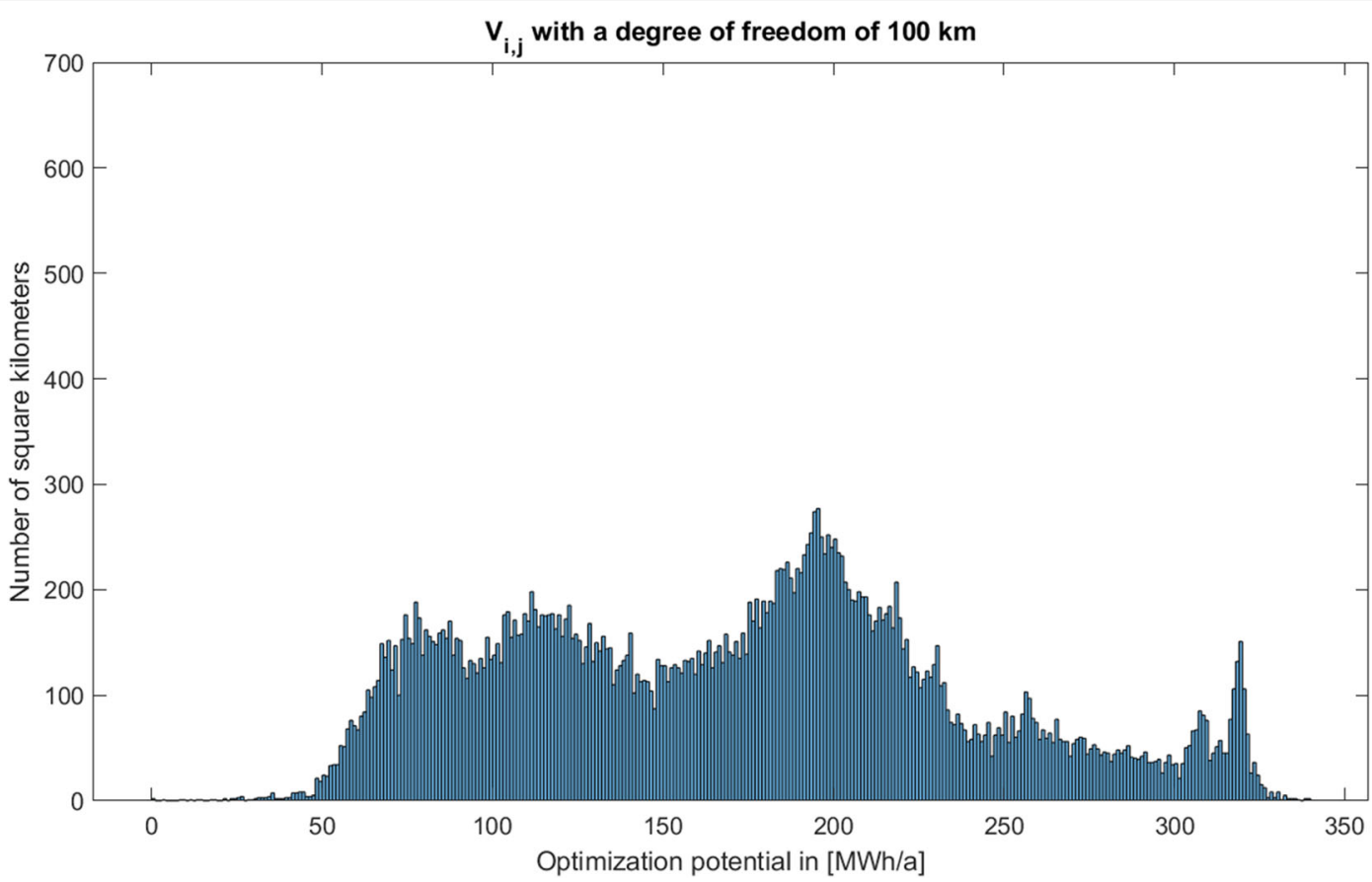

Fig. 12 Histogram of the $100 \mathrm{~km}$ optimization

geographical accessibility, actual data center locations are largely dependent on whether commercial space is currently designated and available for the construction of data centers in the square kilometers studied. This is particularly not the case in nature reserves, residential areas, and on agricultural land. Nevertheless, the consideration of currently undeveloped areas is helpful, since all areas are potentially developable and new areas are regularly developed as commercial or industrial sites. The identified potential could be used as a criterion for allocating new commercial space to advantageous locations and thus specifically promoting the sustainability of data centers in land use planning. However, the transfer of the results presented here to concrete construction projects is only possible to a limited extent, as the time until completion of the building is an important criterion for data center operators. Developers usually only consider existing and designated usage areas, as they cannot wait for new building areas to be designated before building a data center. In order to carry out a potential assessment for concrete construction projects, it is necessary to consider only areas with existing commercial and industrial sites in the land use plan. This can be investigated in a further research project.

\section{Conclusion}

With the model presented in this paper, the influence of small differences in location on the energy consumption of data centers could be quantified. It was shown that even small spatial changes show a relevant difference in energy consumption and thus in their economic and ecological impact.

When building new data centers, a number of factors must be taken into account when choosing a location. If, after taking other factors into account, such as the availability of electricity and fiber optics, trade tax, and land price, there is still flexibility with regard to the possible locations, even small local shifts $(10 \mathrm{~km})$ allow for energy savings of $9.12 \%$ in the chiller system. A medium degrees of freedom $(25 \mathrm{~km})$ allow on average $17.47 \%$ in energy savings and within a radius of $100 \mathrm{~km}$ average savings of $37.35 \%$ are possible. These savings are both economically and environmentally relevant and can be used as a criterion for comparing potential data center locations. The data center infrastructure in the state of Baden-Württemberg and presumably other countries can be made more sustainable if mesoclimatic influences on energy consumption are taken into account in long-term site planning. 
Funding Open Access funding enabled and organized by Projekt DEAL.

\section{Declarations}

Conflict of interest The authors declare that they have no conflict of interest

Open Access This article is licensed under a Creative Commons Attribution 4.0 International License, which permits use, sharing, adaptation, distribution and reproduction in any medium or format, as long as you give appropriate credit to the original author(s) and the source, provide a link to the Creative Commons licence, and indicate if changes were made. The images or other third party material in this article are included in the article's Creative Commons licence, unless indicated otherwise in a credit line to the material. If material is not included in the article's Creative Commons licence and your intended use is not permitted by statutory regulation or exceeds the permitted use, you will need to obtain permission directly from the copyright holder. To view a copy of this licence, visit http://creativecommons.org/licenses/by/4.0/.

\section{References}

Acton, M.; Bertoldi, P.; Booth, J.; Newcombe, L.; Rouyer, A.; Tozer, R. (2018): Best Practice Guidelines for the EU Code of Conduct on Data Centre Energy Efficiency. EUR 29103 EN. Hg. v. Publications Office of the European Union. Luxembourg. Online verfügbar unter http://publications.jrc. ec.europa.eu/repository/bitstream/JRC110666/kjna29103 enn.pdf, zuletzt geprüft am 25.07.2019.

ASHRAE (Hg.) (2016): Data Center Power Equipment Thermal Guidelines and Best Practices. TC9.9. Online verfügbar unter http://tc0909.ashraetcs.org/documents/ASHRAE_TC0909 Power_White_Paper_22_June_2016_REVISED.pdf, zuletzt geprüft am 10.02.2021.

Avgerinou, M., Bertoldi, P., \& Castellazzi, L. (2017). Trends in Data Centre Energy Consumption under the European Code of Conduct for Data Centre Energy Efficiency. Energies, 10(10), S.1470. https://doi.org/10.3390/en10101470 .

Basalisco, B.; Hansen, M.; Haanperä, T.; Dahlberg, E. (2019) Googles hyperscale data centers and infrastructure ecosystem in europe. Economic impact study. Hg. v. Copenhagen Economics. Online verfügbar unter https://www.copenhageneconomics. com/dyn/resources/Publication/publicationPDF/0/500 /1569061077/copenhagen-economics-google-european-dcsinfrastructures-impact-study_september2019.pdf, zuletzt geprüft am 27.07.2020.

Bubel, T (2016): Data center location myths to avoid. In: Site Selection Magazine (July), S. 59-64. Online verfügbar unter https://siteselection.com/digitalEdition/2016 /jul/docs/Site\%20Selection\%20July\%202016.pdf, zuletzt geprüft am 25.09.2018.

Bundesnetzagentur (Hg.) (2020): Monitoringbericht 2019. Bundesnetzagentur für Elektrizität, Gas, 
Telekommunikation, Post und Eisenbahnen. Bonn. Online verfügbar unter https://www.bundesnetzagentur. de/SharedDocs/Mediathek/Berichte/2019 /Monitoringbericht Energie2019.pdf? blob= publicationFile\&v=5, zuletzt geprüft am 25.07.2020.

Data Center Frontier Special Report (Hg.) (2019): Hyperscale data centers. Unter Mitarbeit von Rich Miller. Online verfügbar unter https://datacenterfrontier.com/wpcontent/uploads/2019/09/DCF-Special-Report-HyperscaleData-Centers.pdf, zuletzt geprüft am 20.07.2020.

Depoorter, V., Oró, E., \& Salom, J. (2015). The location as an energy efficiency and renewable energy supply measure for data centres in Europe. Applied Energy, 140, 338-349. https://doi.org/10.1016/j.apenergy.2014.11.067 .

Diguet, C.; Lopez, F. (2019): The spatial and energy impact of data centers on the territories. ENERNUM Project. Unter Mitarbeit von Laurent Lefevre. ADEME.

Norm DIN 4710 (2003) DIN 4710:2003-01, Statistiken meteorologischer Daten zur Berechnung des Energiebedarfs von heiz- und raumlufttechnischen Anlagen in Deutschland.

EnergyNorway (2016): Locations for Data center enterprises (DCE) in Norway. Information to potential investors in Data center enterprises and to developers of new sites for DCEs. Unter Mitarbeit von Liv Bjørhovde Rindal. Online verfügbar unter https://www.ecohz.com/wpcontent/uploads/2016/12/Locations-for-Data-centerenterprises-DCE-in-Norway-17-March-2016-by-EnergyNorway.pdf, zuletzt geprüft am 26.05.2020.

Glatte, Thomas (2017): Kompendium Standortstrategien für Unternehmensimmobilien. Die Standortplanung als Teil der internationalen Unternehmensführung. Wiesbaden: Springer Vieweg (Leitfaden des Baubetriebs und der Bauwirtschaft).

Hintemann, R. (2018) Effizienzgewinne reichen nicht aus: Energiebe-darf der Rechenzentren steigt weiter deutlich an. Rechenzentren 2018. Borderstep Institute. Online verfügbar unter https://www.borderstep.de/wp-content/uploads/2020 /03/Borderstep-Rechenzentren-2018-20200511.pdf, zuletzt geprüft am 09.06.2020.

Icha, P. (2020): Entwicklung der spezifischen KohlendioxidEmissionen des deutschen Strommix in den Jahren 1990 -2019. Unter Mitarbeit von Gunter Kuhs. Hg. v. Umweltbundesamt. Dessau-Roßlau. Online verfügbar unter https:/www. umweltbundesamt.de/sites/default/files/medien/1410 /publikationen/2020-04-01_climate-change_13-2020 strommix_2020_fin.pdf, zuletzt geprüft am 25.07.2020.

Koch, K. (2020): Bestimmen des Energieverbrauchs von Rechenzentren in Baden-Württemberg basierend auf
Klimadaten. Bachelor Thesis. Hg. v. Universität Stuttgart. Institut für Energiewirtschaft und Rationelle Energieanwendung. Stuttgart.

Koomey, J.; Naffiziger, S. (2016) Energy efficiency of computing: What's next? Hg. v. Electronic Design. Online verfügbar unter https://www.electronicdesign.com/microprocessors/energyefficiency-computing-what-s-next, zuletzt geprüft am 25.07.2019.

Krähenmann, S.; Walter, A.; Brienen, S.; Imbery, F.; Matzarakis, A. (2016) Monthly, daily and hourly grids of 12 commonly used meteorological variables for Germany estimated by the Project TRY Advancement. Unter Mitarbeit von Andreas Walter.

Masanet, E.; Shehabi, A.; Lei, N.; Smith, S.; Koomey, J. (2020): Recalibrating global data center energy-use estimates.

Node Pole (Hg.) (2018) Facebook expansion confirms Nordics as leading hyperscale cluster. News. Online verfügbar unter https://www.nodepole.com/NewsArticle/25, zuletzt geprüft am 25.07.2020.

Radgen, P., Turek, D., Wesner, S., Held, F., Mollenkopf, W., Narayanan, M., et al. (2020). Nachhaltige Rechenzentren (EcoRZ). Abschlussbericht: Universität Stuttgart.

Saran, S.; Ramana, K. V. (2018): Site sustainability analysis for industries using GIS and mulit criteria decision making. In: ISPRS Ann. Photogramm. Remote Sens. Spatial Inf. Sci. IV5, S. 447-454. https://doi.org/10.5194/isprs-annals-IV-5447-2018.

Seggern, C. V.; Stasiw, T.; Byron, T.; Parikh, G. (2014) Data Centers. A perspective on site selection, incentives and outsourcing. In: Site Selection Magazine. Online verfügbar unter https://siteselection.com/digitalEdition/2014 /jul/docs/July2014.pdf, zuletzt geprüft am 25.09.2019.

Shehabi, A., Masanet, E., Price, H., Horvath, A., \& Nazaroff, W. W. (2011). Data center design and location: Consequences for electricity use and greenhouse-gas emissions. Building and Environment, 46(5), 990-998. https://doi.org/10.1016/j. buildenv.2010.10.023 .

Song, Z., Zhang, X., \& Eriksson, C. (2015). Data center energy and cost saving evaluation. Energy Procedia, 75, 12551260. https://doi.org/10.1016/j.egypro.2015.07.178 .

Publisher's note Springer Nature remains neutral with regard to jurisdictional claims in published maps and institutional affiliations. 